\title{
POLÍTICA EM DESEQUILÍBRIO PERPÉTUO: CONSIDERAÇÕES SOBRE RELAÇõES DE GÊNERO E GERACIONAIS NA POLÍTICA E NA MORALIDADE KAIOWÁ
}

Politics in perpetual imbalance: considerations on gender and generation relations in kaiowá politics and morality

Diógenes E. Cariaga ${ }^{9}$

\begin{abstract}
Resumo:
Este artigo toma como ponto de partida para reflexões sobre o fazer político e a moralidade kaiowá questões relativas ao prestígio que homens e mulheres, seniores e jovens buscam produzir em suas vidas como estratégias de atrair outras pessoas na produção do fazer político. Para isto, abro a discussão a partir da etnologia canônica produzida sobre os Kaiowa (Guarani) para demonstrar que a ambivalência e a instabilidade da pessoa e dos coletivos não se referem a uma ausência de relações políticas, mas que são formas próprias de produção da vida social. Neste contexto, recorro as narrativas kaiowá sobre os caminhos, criações e transformações do casal demiúrgico formado por Ñande Ramõí ("Nosso Avô") e Ñande Jarý ("Nossa Avó”) e pelos seus filhos gêmeos, Kwarahy ("Sol") e Jasy ("Lua") para realizar algumas considerações a respeito de como as relações de gênero e geracionais nos fazem ver outras formas de prestígio e produção do fazer político entre os Kaiowá.
\end{abstract}

Palavras-chave: Políticas Ameríndias; Moralidade Ameríndia; Etnologia Guarani (Kaiowá).

\begin{abstract}
:
This article takes as a starting point for reflections on political making and Kaiowá morality issues related to the prestige that men and women, seniors and young people seek to produce in their lives as strategies to attract other people in the production of political making. For this, I open the discussion from the canonical ethnology produced about the Kaiowá (Guarani) to demonstrate that ambivalence and the instability of the self and of the collectives do not refer to an absence of political relations, but that are ways of producing social life. In this context, I use the Kaiowá narratives about the paths, creations and transformations of the demiurgic couple formed by Ñande Ramõi ("Our Grandfather") and Nande Jarý ("Our Grandmother") and their twin, Kwarahy ("Sun") and Jasy ("Moon") to make some considerations regarding how gender and generational relations make us see other forms of prestige and production of political action among the Kaiowá.
\end{abstract}

Keywords: Amerindian Politcs; Ameridian Moralities; Guarani Ethnology (Kaiowá).

\footnotetext{
${ }^{8}$ A pesquisa contou com o financiamento do INCT Brasil Plural e CNPq, associada ao NEPI/PPGAS/UFSC e ao Grupo de Pesquisa Etnologia e História Indígena (UFGD). Agradeço à organização do dossiê, ao Léo Braga pelas leituras e comentários, assim como a/o parecerista.

${ }^{9}$ Doutor em Antropologia Social pela Universidade Federal de Santa Catarina (UFSC). Docente do curso de Ciências Sociais (UEMS/Amambai) e do PPGAnt/Universidade Federal da Grande Dourados (UFGD).
} 


\section{Produção de um contexto}

Os coletivos falantes de língua guarani figuram como um dos mais descritos na produção antropológica e etnológica entre os ameríndios nas Terras Baixas da América do Sul. Grande parte da produção clássica, vista desde Nimuendaju (1987 [1914]), centrou-se em definir como fundamento da vida social guarani à religião. A partir do tema da religião guarani preconizava-se a criação e a destruição da existência sociocosmológica dos Guarani, assim como também a suposição que a sua religião estaria passível de desaparecer devido aos processos de integração à sociedade nacional, como escreveu Schaden (1974 [1954]). Movido pelas teorias antropológicas da aculturação, muito prestigiadas na época, o autor se interessou em demonstrar que a "religião tribal guarani" não resistiria aos processos de mudança cultural e caberia aos Guarani o lugar de "índios integrados".

Ambos autores, assim como Cadogan (1959), escrevendo em seu tempo histórico, produziram informações etnográficas valiosas sustentadas em exegeses centradas na religião como eixo da vida guarani. Porém, o tema permanecia afastado dos contextos de relações que entendemos como sociais, como a organização social, parentesco, territorialidade e a política. Este estilo de etnologia deu prevalência a um problema que, ao mesmo tempo em que se assenta sobre os humanos, se afasta deles: a dualidade celeste versus terrestre que coexiste no ñeêe, que ficou canonicamente traduzido como "alma-palavra" que é também como se traduz e se compreende a língua (no sentido de idioma) e a linguagem (como comunicação $)^{10}$, mas sempre cerceadas pela ideia de uma dita "religião guarani".

As questões que pretendendo delinear neste texto foram extraídas de minha tese de doutorado a respeito dos modos de fazer e desfazer coletivos entre os Kaiowá por meio de homens e mulheres personagens da ação política (CARIAGA, 2019). A etnografia apresentada procurou seguir reflexões guiadas por um percurso que dá relevo a instabilidade de relações engendradas através de dualismos imanentes a ontologia guarani. A instabilidade é entendida como efeitos de movimentos que conduzem a vida social associados na diferenciação constante entre personagens, planos, patamares celestes e humanos que principiam de uma mesma existência, que são desdobramentos de si e entre si. Esses movimentos possibilitam seguir categorias e conceitos referentes a uma sociocosmologia que recusa a se render ao processualismo histórico derivado da intensificação das relações com a sociedade nacional ${ }^{11}$.

As reflexões que procurei realizar na tese e que espero sintetizar neste artigo são tributárias às proposições de Hélène (2007) e Pierre Clastres (2003; 2004) em extrair das falas, discursos e da literatura sobre os Guarani uma dimensão filosófica e política do pensamento. As questões pensadas pelo casal Clastres derivadas da ambivalência entre o político e o religioso, o humano e o celeste e no profetismo, têm alimentado um conjunto de reflexões na etnologia sobre os coletivos falantes de guarani por meio de concepções acerca dos conceitos e categorias sobre a noção de pessoa, de sociedade e de natureza. Como sintetizou Viveiros de Castro (1987: xxxiii) a respeito do que escreveu Hélène Clastres: "A ela devemos a consolidação da teoria Guarani sobre o Homem, que o põe como lugar de compromisso instável e perigoso, travado na temporalidade, entre o animal e o divino, essas duas formas simétricas do não-ser social".

${ }^{10}$ O material bibliográfico disponível sobre o assunto abunda e transborda na literatura guarani. Como referências, indico as súmulas produzidas por Melià (2016; 2004), Melià, Saul e Muraro (1987). Especificamente sobre os Kaiowá, menciono as pesquisas de Chamorro (2008; 1995) e Melià, Grünberg e Grünberg (2008).

${ }^{11}$ Kaiowá é o nome dado a um coletivo falante de língua guarani que vive majoritariamente no sul do Mato Grosso do Sul, em uma extensa região de transição entre a Mata Atlântica e o Cerrado, profundamente impactada por frentes extrativistas e agropastoris desde o fim do século XIX. Atualmente, são cerca de 45 mil pessoas, sendo que a maioria vive em ínfimas porções de terra criadas pelo Serviço de Proteção aos Índios (SPI) no início do século XX. Desde a promulgação da Constituição Federal, aguardam a consecução dos processos de identificação e demarcação de terras para reaverem seus territórios de ocupação tradicional. 
Esta ambivalência que permeia e atravessa a vida entre os coletivos falantes de língua guarani nos coloca um desafio que é seguir multiplicidades enredadas por uma metafísica onde as palavras, narrativas e discursos que emergem na interlocução com as pessoas em campo são possibilidades de acessar e vislumbrar um conjunto de relações entre transformações que esmaecem dualismos como natureza e sociedade. A respeito disto, Viveiros de Castro ao propor linhas de um "princípio geral" (1986) à etnologia guarani, e posteriormente, tupi-guarani, reposiciona a ambivalência clastreana para a constituição do próprio modo de ser entre os Guarani, distanciando a escatologia e o esoterismo: "a Sociedade ela mesma é uma margem ou fronteira, um espaço precário entre a Natureza (animalidade) e Sobrenatureza (divindade)" (1986: 115). A proposição etnográfica do autor indica um modo de desdobrar séries cosmológicas e sociológicas para uma figura conceitual triádica que propiciou pensar a noção de pessoa em cosmologias tupi-guarani, estruturada em três séries: uma animal, uma humana e uma divina (ibidem).

As explorações conceituais de Viveiros de Castro $(1987 ; 1986)^{12}$ abriram uma senda para renovação das etnografias guarani aproximando-as de outros contextos ameríndios, colocando em comparação os dados etnográficos aos materiais amazônicos sobre teorias da corporalidade, tempo e espaço. Neste sentido os trabalhos de Montardo (2009), Ladeira (2007), Pissolato (2007) e Pereira (2004) são referenciais ao estímulo de retomada aos trabalhos de pesquisa junto aos coletivos falantes de língua guarani. Em comum, a bibliografia citada contraria o pessimismo de Nimuendaju (1987 [1914]) e as imagens de aculturação de Schaden (1974 [1954]), que postulavam não haver mais necessidade de escrever a respeito dos Guarani diante do seu inevitável fim.

Deste modo, o que pretendo realizar neste artigo retoma o diálogo com o tema da ambivalência, mas com o intuito de demonstrar que isso está longe de ser o "grande mal dos Guarani" (1974 [1954]) tal como dito por Schaden, para quem este traço expressava uma ausência de coesão social do grupo. Neste sentido, a imprecisão provocada pela teoria guarani da pessoa conduz a uma leitura na qual a instabilidade agencia uma multiplicidade de relações engajadas em torno de concepções nativas que emergem em narrativas de criação e transformação mitológicas e cosmológicas entre os Kaiowá e nos aproxima daquilo que Claude Lévi-Strauss (1993) indicou como estrutural ao pensamento indígena: o dualismo em desequilíbrio perpétuo e a abertura ao outro.

$\mathrm{Na}$ teoria lévi-straussiana tal movimento pendular estabelece uma assimetria constante que obriga as categorias do pensamento a produzir conjunções e disjunções, podendo ser notada em toda vida social ameríndia. Em História de Lince (LÉVI-STRAUSS, 1993) a gemelaridade é posta como guia para a compreensão da ideologia bipartite no pensamento ameríndio para se demonstrar que, mesmo onde se vê apenas semelhanças, estamos no domínio das operações que asseguram a possibilidade de desdobrar dualismos como natureza e sociedade ora como domínios ontológicos e outras ocasiões mobilizá-los como categorias antropológicas para a análise.

Pretendo seguir um conjunto de narrativas kaiowá para refletir a respeito de acontecimentos anteriores ao nascimento dos gêmeos míticos Kwarahý ("Sol”) e Jasy ("Lua"), com o propósito de dar uma maior atenção as relações inauguradas pelas diferenças entre o casal demiúrgico Ñande Ramõí ("Nosso Avô") e Ñande Jary ("Nossa Avó"). O primeiro tema, o dos gêmeos, está presente desde os registros iniciais da etnologia guarani. Em grande parte do material o que se acentua é a importância da senioridade e maturidade da condição da pessoa (agwyje $)^{13}$ produzidas pelos caminhos e criações originadas pelos irmãos. Contudo, tal

\footnotetext{
${ }^{12}$ A Cito aqui duas obras de Viveiros de Castro, mas em minha tese (CARIAGA, 2019) desenvolvo reflexões sobre uma produção etnográfica mais extensa sobre os efeitos de sínteses e modelos analíticos realizados com base em pesquisas com indígenas nas terras baixas a partir da década de 1970. Entretanto, no caso de um modelo analítico Tupi-Guarani, tal movimento foi marcado pela publicação dos textos apresentados no I Encontro Tupi acontecido em 1984 em um dossiê publicado na Revista de Antropologia (USP), volumes 27 e 28, 1984/1985.
} 
centralidade etnográfica acabou eclipsando outro conjunto de relações estruturantes à mitologia, à cosmologia e à ação política kaiowá geradas pelas diferenças entre homens e mulheres. Tal encobrimento acabou por produzir uma impressão de que se tratava de uma "cultura marcadamente masculina" (SCHADEN 1974 $[1954])^{14}$. Assim, o que lerão aqui neste artigo também (per)segue questões colocadas por Strathern (2014; 2006; 2001) sobre as comparações entre relações, que avalio que possam torna possível ver na socialidade kaiowá composições, conjunções, alternâncias entre e através de homens e mulheres, seniores e juniores, a fim de extrair da mitologia princípios éticos que constituem o desafio da moralidade ameríndia: a boa distância entre seres, planos e patamares humanos e não-humanos (LÉVI-STRAUSS, 2006).

\section{Kuimba’e reko e kuña reko: notas sobre as diferenças (como políticas) entre homens e mulheres kaiowá}

Durante a realização da minha pesquisa interessada em descrever os modos de fazer e desfazer coletivos e lideranças entre os Kaiowá me deparei com uma observação inquietante sobre a centralidade do prestígio atribuído aos homens em detrimento às mulheres que eram vistas e se apresentavam como lideranças ${ }^{15}$. Mesmo reconhecendo o limite do termo, lideranças é a palavra usada em língua portuguesa pelos Kaiowá para se referirem a homens e mulheres que atuam como atratores de outras relações, que produzem e investem meios para dar suporte para um coletivo. No contexto das falas e discursos kaiowá as palavras utilizadas como tradução para este conceito são grupo ou turma. O uso dessas palavras indica que pode existir muitos modos de se entender grupo/turma, podem ser de parentes, de rezas, de aliados políticos (até mesmo não indígenas), igrejas, movimentos indígenas e indigenistas. Enfim, não caberia aqui um inventário de práticas e modos de ação, mas o que destaco é que homens e mulheres, jovens e seniores, podem desejar esta condição de ser liderança de um grupo, porém, isto esbarra em questões sobre o prestígio necessário para atrair pessoas para seu grupo.

Como me referi acima, a etnografia sobre os Guarani foi conduzida por perspectivas que centralizam a vida nas questões ditas religiosas, dando proeminência ao papel dos homens seniores reconhecidos pela conduta da vida familiar, xamânica e aos cargos instituídos através das políticas de territorialização iniciadas pelo Estado no início do século XX. No contexto das redes kaiowá, os homens xamãs são chamados de ñanderu e as mulheres de ñandes $y^{16}$. Os ñanderu assim como em outras paisagens ameríndias são personagens que condensam em si muitas relações. No contexto kaiowá a expressão do prestígio é gradual à medida que avançam na idade, têm filhos e principalmente netos, são eles que garantem aos homens a condição de ramói (avô). Percebo que entre os Kaiowá modulam-se diferenciações do prestígio que a idade pode conferir a uma pessoa, que isto está condicionado há elementos que indicam a capacidade de estabilizar sua família em no mínimo três gerações: avós, filhas e filhos (genro e nora) e netos. A frente retomarei isto, porém, no momento, volto-me a questão do ocultamento do prestígio que as mulheres ocupam na condução da vida social e política.

\footnotetext{
${ }^{13}$ Pierri (2018) em sua etnografia sobre o tema da perecibilidade e imperecibilidade entre os Mbyá, revisita o tema e oferece uma perspectiva revigorante sobre a instabilidade e multiplicidade entre os falantes de língua guarani

${ }^{14}$ Na bibliografia kaiowá, somente a etnografia de Seraguza (2013) procurou revisar a literatura e apontar um ponto de vista das mulheres sobre o poder e o prestígio.

${ }^{15}$ As pesquisas em etnologia indígena que tem tratado das questões sobre o tema da política, da chefia, da liderança e seus desdobramentos, como os personagens da ação política, veem estabelecendo uma crítica produtiva sobre o limite dos termos que utilizamos para se referir às relações indígenas que atribuímos qualidades do fazer político. Não irei realizar um panorama deste debate, mas menciono aos leitores as proposições de Perrone-Moisés (2015; 2011) e Sztutman (2012) que iluminam problemas etnográficos acerca dos termos ameríndios que agenciam estratégias de recusa e de aproximação com seus outros. Entre os Kaiowá as etnografias de Pimentel (2012) e Pereira (2004) são centrais para a compreensão de uma teoria kaiowá das suas relações políticas
} 
Meu interesse em seguir personagens da ação política entendidos como lideranças esbarrou na observação que havia um baixo rendimento nas etnografias kaiowá sobre as dimensões do prestígio das mulheres na vida social, ao perceber que para todo termo de prestígio masculino, existe um para o feminino. Isto me indicava que as qualidades necessárias para se fazer uma liderança não se restringiram ao gênero, ou melhor dizendo, aos homens. Em 2015, quando fazia campo na Aldeia Jaguapirú ${ }^{17}$, acompanhei um Jerosy Puku ${ }^{18}$, no qual homens e mulheres cantam-rezam juntos, onde os ñanderu puxam os cantos portando seus xíru e mbaraka (respectivamente, uma insígnia ritual e o chacoalho identificados como prioritariamente masculinos), e as ñandesy se posicionam atrás com seus takuapu (bastão ritual feito de taquara) no momento das rezas. Ao perguntar para Dona Alda, anfitriã da festa com seu esposo Getúlio, sobre a posição das mulheres no Jerosy Puku, ela me respondeu dizendo que o fato das mulheres estarem atrás não fazia delas figuras secundárias ou menos importantes da condução do canto-reza, mas que a imagem que eu via demonstrava que as coisas entre os e as Kaiowá são feitas de maneiras diferentes entre homens e mulheres, pois para os Kaiowá existe o kunã reko e o kuimbae reko, respectivamente, "modo de existir das mulheres" e "modo de existir dos homens".

Esta conversa reteve minha atenção, pois desde o mestrado (CARIAGA, 2012), notava certa correspondência entre os termos de prestígio que orbitam em torno da importância do casal e do casamento para homens e mulheres, não apenas pela conjugalidade, mas pelas relações agenciadas por, através e entre mulheres e homens para além do dimorfismo sexual e das categorias etárias. O que move tais relações é a potência em conjugar e alternar qualidades/capacidades presentes desde a vida cotidiana até às narrativas míticas, a cosmologia e condutas pessoais e de coletivos. Deste modo, as relações políticas entre os gêneros e entre as gerações ora se expressam na mitologia, ora na cosmologia e na moralidade. Neste sentido, os mitos atuam como ponto de partida para compreender como as formas de conjunção e disjunção entre homens e mulheres, seniores e jovens compõem muitas qualidades do que se é pensado enquanto prestígio para as famílias e lideranças kaiowá.

A conversa com Dona Alda me sugeria uma possibilidade de mobilizar uma maior atenção a descrições etnográficas sobre mulheres e homens entre os Kaiowá. Alimentava minhas suspeitas de que a ausência de atenção ao que se passou antes do nascimento dos gêmeos míticos kaiowá e claro, com a mãe deles, implicou no esmaecimento de Ñande Jarý. Mas como aponta Seraguza (2013: 26), a prevalência desta perspectiva no material guarani trata-se de um problema etnográfico: "a concentração dos estudos etnográficos a partir da socialidade masculina é o gancho e o gargalo para as teorias de gênero na Antropologia, bem como a possibilidade de percepção de um conceito nativo sobre as relações de gênero". Assim, se a produção de pessoas é central ao mundo ameríndio, pensava que situações vividas pelo pai e pela mãe de Kwarahy e Jasy, poderia ter algum rendimento etnográfico para as reflexões que possibilitariam delinear algumas considerações sobre as

\footnotetext{
${ }^{16}$ A palavra é uma contração de ñande (nós, nosso) e ru (Pai). Ela é utilizada tanto no sentido genealógico, para indicar um pai de um grupo de irmão e irmãs, como também se refere ao xamã humano, ñanderu. Os demiurgos celestes, como Kwarahy e seu pai, Ñande Ramõi, também são entendidos em ambas chaves: no sentido das relações de descendência, como pai/avô e como "xamãs hipermagnificados para os Kaiowá (CARIAGA, 2019). Já ñandesy é a junção de ñande (nossa) e sy (mãe), de modo análogo ao que descrevi, o termo é utilizado tanto as mulheres xamãs e a mãe/avó primordial, Ñande Jarý.

${ }^{17}$ Tenho atuado desde 2004 em diversas atividades de pesquisa, assessoria e colaboração junto às famílias kaiowá da região do Ka'agwyrusu, área localizada na bacia do Rio Dourados. Na pesquisa de doutorado concentrei o campo nas áreas indígenas localizadas entre os rios Brilhante e Dourados, atualmente sobrepostas e recortadas por vários municípios, distritos, rodovias e áreas de monoculturas.

${ }^{18}$ Não terei tempo neste artigo de discorrer sobre o Jerosy Puku. De modo muito sucinto, trata-se de um conjunto de cantos-rezas e danças para Jaikara, "Dono das Plantas Agrícolas", marca o calendário agrícola kaiowá, no qual um casal de xamãs (ñanderu e ñandesy) convidam outras pessoas para cantarem-dançarem-rezarem juntos. Para se informar mais sugiro a leitura de Gibram e Klein (no prelo), João (2011) e Chamorro (2008).
} 
relações entre homens e mulheres entre os Kaiowá. O elemento indiciário na conversa com Dona Alda atiçou a minha curiosidade, levando-me a trazer o assunto em conversa com outros casais de rezadores.

A primeira vez que provoquei o tema, foi com Dona Floriza, nhandesy kaiowá, casada com Seu Jorge, também rezador/nhanderu e residentes com sua família na Aldeia Jaguapirú em Dourados. O mote do início a uma série de diálogos teve como ponto de partida a razão do desentendimento entre Nande Jary e Ñande Ramõí. Entre muitas frases e expressões ditas por Dona Floriza, quando perguntei a ela como poderia entender "as histórias do tempo dos antigos", modo mais recorrente entre os Kaiowá para referirem ao tempo/ espaço mítico (ara ymagware), ela disse-me:

O tempo desses antigos (Ara Ypype), antigos mesmo, mito que nem vocês falam, era o tempo que tudo era novidade. Não tinha nada, daí foi que Nosso Vovô (Nhande Ramõi) e Nossa Vovó (Nhande Jarý) foram fazendo tudo que o Kaiowá precisava, por isso que tudo na história Kaiowá tem lugar, sempre tem uma história para contar porque a gente vive assim hoje, porque no jeito dos Kaiowá tradicional, tudo tem um cuidador, tem uma origem. Por isso que a gente chama no nosso idioma de Nhande Jara Kwera (Nossos Donos-Cuidadores).

No tempo/espaço primordial (Ara Ypype), o mundo kaiowá parecia ser muito pequeno, porque tudo que o casal precisava estava por perto, não era preciso sair da ogusu (casa comunal) em que residiam ou percorrer longas distâncias porque tudo era próximo. Segundo Chamorro (2008), a cosmogênese kaiowá é marcada pela existência de algo, uma agência/potência, que é anterior aos entes celestes, chamada de Jasuka. Segundo a autora Jasuka é uma espécie de "princípio ativo do universo" (CHAMORRO: 123). Citando Cadogan, a autora nos diz que Jasuka é a origem de tudo, até mesmo dos deuses; que enche e inclui o Universo, pai de todos e de tudo (CADOGAN apud CHAMORRO, 2008: 123). Jasuka é a bruma das manhãs que emana da terra que tem o poder de renovar o corpo e restaurar os comportamentos violentos e agressivos das pessoas (teko pochy), assim como restaurar o bem-estar das plantas agrícolas, animais e das matas. Ancorando-se na revisão do material guarani (Nimuendaju, Cadogan e Meliá), Chamorro (2008: 130-132) chama atenção para um elemento importante na metafísica guarani, que também foi notado por Bartolomé (2009) e Clastres (1990) entre os Mbyá, que é a própria existência-ação de personagens que são criadores/as de si e do cosmo. Entre os Kaiowá tudo provém de Jasuka, assim como para os M’byá é de Nhamandu, este ser que se cria e se desdobra, começo e fim (CLASTRES, 1990).

Seguindo o texto de Chamorro (2008), mediante sua análise do material de Cadogan sobre os diversos simbolismos, metáforas e analogias linguísticas no campo dos estudos da religião, a antropóloga concluiu que Jasuka é a substância-mãe, sendo generativa do universo. Não pretendo discorrer sobre os equívocos da objetificação do gênero de Jasuka, mas vale à pena notar a controvérsia identificada pela autora no material guarani na qual o Ser Criador do cosmo é notadamente marcado no masculino, entretanto, antes dele não havia o caos, pois Jasuka já existia. Expressando o limite de tomar o mundo guarani como originalmente derivado da existência de um único ente masculino, Chamorro (2008: 123) escreveu: "esse ser (o Criador) não é infinito pois em um começo e depende de algo anterior a ele: uma substância criadora e mantenedora da vida, Jasuka".

Sugiro pôr em destaque esta ambivalência produzida pela autora (idem), aproximando-a ao debate melanésio da existência da pessoa andrógina na produção do gênero (STRATHERN, 2006), isto permitirá compreender que a objetivação do gênero de Jasuka faz sentido etnograficamente porque é a forma pela qual Chamorro (idem) cria uma condição de análise pré-mítica (antes da existência do que ela chama, de heróis culturais, os gêmeos Paí Kwára e Jasy) para requalificar o prestígio das mulheres, sublimados por décadas de trabalhos que não viam as relações de gênero e, entre os gêneros, como relações políticas. 
Assim, as relações de gênero oferecem uma perspectiva possível de ser comparada. As pessoas e coletivos atuam como partes e todo na produção da socialidade "pois eles vivem em mundo no qual as perspectivas assumem uma forma particular, qual seja, a das analogias. Como resultado, suas perspectivas podem ser trocadas uma pelas outras" (STRATHERN, 2014: 249).

Neste plano, as formas melanésias de objetificação sobre os gêneros projetam um recurso descritivo importante para compreensão das dinâmicas convencionalizantes em que transformar os modos como gênero é classificado e simbolizado como relação, ganha sentido se seguirmos como as pessoas atribuem valor as relações à medida em que só são reconhecidas se assumem uma forma específica (STRATHERN, 2006: 273). Entre os Kaiowá tal assunto rende, pois para se chegar ao entendimento que existe um kuña reko e um kuimbaée reko é preciso notar suas possibilidades de comparação analógicas e metonímicas entre os conceitos nativos. Todavia, não foi pela existência de Jasuka que as relações entre homens e mulheres kaiowá desde o "tempo dos antigos mesmos" como me disse Dona Floriza, se tornaram o tema de nossas conversas, mas foram as questões da ordem cotidiana que causaram a divergência entre o casal primordial, como os sentimentos, as tarefas domésticas, $\mathrm{o}$ cuidado com os filhos e com o roçado foram os assuntos que deram início às nossas reflexões conjuntas.

Dona Floriza e Seu Jorge foram enfáticos em me dizer que existem coisas que são dos homens e coisas que são das mulheres, com uma tradução que encontram para me informar do que se tratava os conceitos kuimba'e reko - coisas, conhecimentos, jeitos e modos de ser inerente aos homens e o termo correspondente para as mulheres, kunhã reko. Ao longo da descrição, Seu Jorge produzia uma cena com as mãos, colocando-as à frente do meu rosto justapondo-as para esclarecer que não existia quem era mais importante, porque em sua explicação ele frisava que todos nós precisamos das duas mãos e, no corpo, elas têm a mesma proporção. Acontece que, segundo ele tem coisas que a essa mão aqui (projetando a mão direita) faz melhor e outras essa daqui (com a esquerda) tem mais jeito. Homem e mulher são assim.

Dona Floriza passou a destacar uma série de seres, plantas e ambientes que eram de estima e cuidado de Nhande Jarý, como as plantas que nascem próximas de brejos e nascentes de rio, que são remédios do mato exclusivos a saúde das mulheres (kuña pohã kaagwyre). Segundo o relato da ñandesy havia também os animais e insetos que foram criados por Nhande Jarý, como os grilos que eram vistos pelas aves que ela criou como a juruty (pomba do mato), nambuí (codorna) e ynambu (perdiz) como seu amendoim. Já Nande Ramõi tinha grande apreço pelas coisas que viviam nas matas (kaagwy rusu) e com espécies de árvores com o yary (cedro), tajy (ipê), vyrapyta (peroba). O casal compartilhava a responsabilidade do cuidado com as roças de mandió (mandioca), jety (batata), kumanda (feijão), andaí (abóbora). As plantas cultivadas forma presentes de Jaikara Gwasu, o "Dono das plantas agrícolas", para o casal. Inclusive, foi um comportamento inadequado de Ñande Ramõí com a roça de Jaikara que teria iniciado a contenda dos cônjuges.

Certo dia, Jakaira comunicou à Nande Ramõi que ele poderia ir a sua roça (kokuê ypype) coletar alguns produtos para o consumo do casal. Chegando lá, ele pegou as espécies de costume, mas avistou uma planta nova, muito bonita. Retornando a casa comentou com Nande Jarý a respeito da beleza e o desejo de comê-la. A esposa grávida, disse que os filhos em sua barriga, ouviram e ficaram com muita vontade de comer, porém, o esposo disse que não poderia colher o produto porque não havia sido autorizado pelo dono da roça. Tal argumento não foi suficiente para convencer a esposa, que ficou insistindo, exigindo e brigando com o marido para que ele pegasse a planta, mesmo sem o consentimento de Jaikara.

Assim, para não aumentar a briga conjugal, Nande Ramõi, foi até roça antes que o dia amanhecesse atendendo ao pedido de sua companheira, mas foi surpreendido por Jaikara que condenou sua atitude, dizendo que o comportamento havia sido uma quebra na relação de confiança e daquele momento em diante seria necessário aguardar que o produto da roça, o avati morotĩ ficasse maduro (agwje) para o consumo. A ação de Ñande Ramõi obrigou Jakaira a colocar regras para a colheita o preparo para fins alimentícios do avatí morotĩ, 
chamado em português pelos Kaiowá de milho branco ou milho saboró, alimento desejado por Ñande Jarý na gestação dos gêmeos. Desde então é preciso esperar o tempo de maturação das espigas e é preciso fazer um jerosy puku (canto-reza de longa duração) para tornar o avatĩ morotí em alimento. Todas estas recomendações existem porque o avatĩ morotí também é um ente celeste, o próprio Jaikara Gwasu. Esta condição faz com que ele retenha uma parte potencialmente perigosa, devido a sua origem celeste e para se tornar algo possível de ser consumido demanda a realização do conjunto ritual de cantos-danças-reza que é o Jerosy Puku ${ }^{19}$

Esta situação, segundo Dona Floriza e Seu Jorge, foi o que desencadeou as divergências e desentendimentos entre o casal demiúrgico após uma longa briga que tiveram que, na opinião de Dona Floriza, fora motivada pela incapacidade de Ñande Ramõi (e dos homens em geral) de realizarem tarefas e ações sozinhos. Isto é, a vida dos homens, na opinião das mulheres, é marcada por uma relação de cooperação e dependência com as mulheres e de sua família. Isto foi notado por Pereira (2004) que demonstrou que a vida social e política dos homens kaiowá é marcada pela dependência das relações de conjugalidade e afinidade relacionados à categoria che ypyky kwera ${ }^{20}$, que o autor traduz como "fogo doméstico". O autor aponta que o termo $y p y k y$ remete às origens. Kuera é um sufixo de aglutinação (meus antepassados). Na língua guarani é necessário o uso de pronomes possessivos como che (meu, minha, nosso, nossa) ou demonstrativos como nde (teu, tua) ao se referir a algo pessoal, de propriedade ou pertencimento, então, che ykypy kwera alude a compreensão de que a existência da pessoa prescinde que ela pertença (no sentido de relações políticas) a uma família extensa ${ }^{21}$.

Tanto Pereira (2008), quanto Seraguza (2013) enfatizam que a conjugalidade potencializa o prestígio das pessoas, mas que, a falta de laços conjugais-familiares é mais prejudicial aos homens do que as mulheres, sendo possível verificar a existência de fogos domésticos liderados apenas por mulheres viúvas ou separadas. A conjugalidade não é sinônimo de casamento, tal relação pode ser vista como uma ação capaz de conjugar atributos e qualidades dos saberes e poderes das mulheres (kunhã reko) e dos homens (kuimbaẽ reko), que podem ser combinados através de muitas formas de associação: irmãos e irmãs, tios e sobrinhos, tias e sobrinhos, avós e avôs, enfim, a centralidade não é o casamento em si, mas a composição entre homens e mulheres.

\section{Criar e transformar}

A dependência de homens e mulheres as relações conjugais como modo de estabilização da força política de um grupo, na perspectiva de Jorge e Floriza, seria decorrente das atitudes tomadas pelo casal

\footnotetext{
${ }^{19}$ Os pesquisadores kaiowá Izaque João e Misael Concianza me disseram que é preciso investigar com os nhanderu e nhandesy mais experientes a suposição que os seres celestes aprenderam as rezas com Jakaira, porque sendo ele o dono do produto mais importante da vida ritual kaiowá, o milho branco, é quase certo que teria sido ele quem ensinou o primeiro Jerosy Puku aos outros tekojara (donos dos modos kaiowá de ser), que depois ensinaram aos humanos. Izaque sempre era enfático em dizer que todos os cantos-rezas dos Kaiowá se originam do Jerosy Puku, ou seja, ele mesmo se tornou um dono e é o próprio canto-reza principal.

${ }^{20}$ O modelo de organização social e parentesco proposto por Pereira (2004) evoca a ação de contração e expansão das relações associadas aos princípios sociais nativos como ore e pavêm. Sobre isto situa o parentesco numa escala minimalista iniciando a descrição do fogo doméstico, que é para o autor a categoria mais elementar do parentesco, referente ao grupo familiar chefiado por um casal, que reúne seus descendentes, genros, noras, netos residindo temporariamente e os filhos adotivos. É a partir da descrição do fogo doméstico e das dinâmicas de produção de aliados e cônjuges que o autor elabora uma teoria do parentesco kaiowá como uma forma de produção de gradientes de afinidade e de distanciamento como uma estratégia de alianças matrimoniais, para se casar no limite das relações de afinidade nos limites do coletivo, isto é, no tekoha, mas evitando práticas incestuosas e constrições endogâmicas.

${ }^{21}$ Além do já mencionado trabalho de Pereira (2004), sobre o tema da pessoa kaiowá a etnografia de Tonico Benites (2009) e a que realizei no mestrado (CARIAGA, 2012), demonstra que nascer não garante a pessoa o status de humano entre os Kaiowá. Tal condição é sustentada pelas relações que o parentesco garante a produção da pessoa.
} 
celeste e pelas idiossincrasias de cada um: Ñande Ramõí é tido como muito individualista, pouco atencioso aos pedidos da mulher grávida e, por sua vez, Ñande Jarý é vista muito crítica e briguenta, razão pela qual o marido não suportou mais a convivência e a abandonou na plataforma terrestre yvy ypy (terra antiga, terra primordial) ${ }^{22}$. A decisão de Nande Ramõi, no ponto de vista de todos os/as xamãs que conversei sobre o assunto marcou um tempo de intensas transformações na cosmografia kaiowá, pois sua atitude desencadeou uma série de caminhos e criações que estruturam uma ontografia ${ }^{23}$ do mundo kaiowá.

O que penso através das narrativas sobre o casal primordial e seus filhos gêmeos são possibilidades de pôr em destaque formas criativas de engajamento de xamãs, conhecedoras/es e lideranças kaiowá na produção de narrativas míticas e cosmológicas como uma forma de ação política contemporânea contra as práticas de poder estatais e não indígenas que tentam torná-los menores, no sentido de tratá-los como uma versão fraca do que já foram e viveram quando viviam no "modelo tradicional", recorrendo a uma estética culturalista que não é indígena, mas sim do Estado. Outro modo de se aplicar uma força de contenção da criatividade é também acusar que aos indígenas faltam categorias como gênero, violência de gênero, juventude e adolescência.

As narrativas míticas sobre criação e transformação kaiowá não são referências estáticas há um passado idílico sobre o qual meus interlocutores/as demonstraram muitas vezes nunca ter existido, mas ao falar dos e sobre os mitos é colocá-lo em movimentos reflexivos que desafiam suas próprias categorias nativas a abrirem-se e desdobram-se em outras. Neste sentido não avalio que ao refletirem sobre os acontecimentos vividos no tempo mítico, as pessoas com quem dialoguei estivessem equiparando tais relações a categorias sociais da vida não indígena e, do mesmo modo, não as transponho para a vida social kaiowá, mas que venho demonstrando (CARIAGA, 2019; 2012) que há um investimento criativo potente do pensamento kaiowá em sustentar condições de existência, a partir de seus próprios termos e conceitos, o ingresso de outras regimes de conhecimentos, tecnologias e poderes ao seus modos de existência - ore reko.

Creio que meu interesse em saber mais das histórias dos tempos dos antigos, para compreender as transformações nos modos e estilos de liderança, recuando-as para um momento anterior ao "marco zero da mitologia guarani", a saga dos Gêmeos, estimulou as pessoas a falarem e refletirem sobre os caminhos tomados por Nande Jarý e Ñande Ramõi. Nestas reflexões colocadas em nossos diálogos não podem desconsiderar os efeitos da circulação das pessoas em circuitos acadêmicos, de pesquisa, em debates políticos eleitorais onde passaram a dialogar com políticas públicas e demandas de organização coletiva impulsionadas pela agenda dos temas relacionados a categorias de gênero e geracionais. Estas inovações asseguram as mulheres, jovens e aos homens a produção de novas formas kaiowá de socialidade, produzindo um campo de traduções que podem comunicar aos brancos alguns modos kaiowá de relações com os saberes, poderes e tecnologias dos brancos (CARIAGA, 2019; SERAGUZA, 2018).

Pensar sobre as diferenças entre mulheres e homens e vice-versa, ocupou muito dos meus diálogos com Seu Jorge e Dona Floriza. Em uma das nossas conversas, Seu Jorge deu sequência à história do desfecho

\footnotetext{
${ }^{22}$ Como notado por Seraguza (2013), entre suas interlocutoras de Yvy Kuarusu/Takuaraty, somente às mulheres cabe o adjetivo ñaña (briguenta) devido a uma continuidade ontológica das mulheres à figura de Aña, ser antissocial e trickster das criações de Paĩ Kwára. Na variação exposta pela autora, compete a Aña o papel de imitar os atos e ações de criação de Paĩ Kwára que é criador homem e Aña da mulher, mas inicialmente dotada de atributos corporais e morais animalescos. Coube a Paĩ Kwára retirar as características e qualidades animais da criação de Aña, garantindo assim sua humanidade

${ }^{23}$ Procuro fazer uma conexão com o conceito de ontografia proposto por Hoolbrad a partir das disputas em torno da noção de verdade e representação nas práticas divinatórias do Ifá em Havana (2003: 63). O argumento de que o oráculo de Ifá age de modo diferente do senso comum, porque "trabalha para identificar as conjunções que ligam os eventos a sua causa, o oráculo opera lateralmente, estabelecendo pontos de colisão entre trajetórias causalmente independentes de eventos". Não estou estabelecendo uma homologia às narrativas míticas kaiowá ao oráculo de Ifá, mas me conecto a ideia do autor de que existem formas de fazer mundos que desafiam a noção de verdade, porque tem no movimento sua matéria-prima.
} 
da briga entre Ñande Ramõi e Ñande Jary, que culminou no abandono dele da residência devido à reação de sua esposa, que não aceitou ser maltratada por ele (omenda jeheái). Segundo o casal de xamãs, logo que Ñande Ramõi tomou a decisão de partir levou consigo seus adornos corporais (ponchito, chiripa, jeguaka - peças da indumentária utilizada nas festas) e seus artefatos de reza (mbaraká, mymby, xiru, gwyrapara). Ao sair pela porta da casa na direção ao leste (kwarahy rese - onde o sol sai) foi entoando um canto-reza primordial (ñembóe ypyrumby) que foi tomando a forma de uma escada que possibilitou que ele pudesse criar um caminho (tape rendy) rumo a morada celeste onde ele passou a viver junto ao Xiru Kurusu, onde vive até hoje, no patamar celeste mais elevado da cosmografia kaiowá, o Kurusu Ambá.

Todavia, este caminho criado não tinha duas vias (ida e volta) porque durante o trajeto de subida através do céu (o’jupi yvaga) as rezas pronunciadas por Nande Ramõí fizeram com que fossem criadas camadas de tempo-espaço (ara joguy) para que sua esposa não pudesse alcançá-lo. Desta forma, a ação da reza de Ñande Ramõí fez com que se expandisse o mundo kaiowá verticalmente. O plano celeste kaiowá foi estruturado a partir de cantos-rezas que foram criando domínios celestes guardados pelos auxiliares/parceiros (yvyrayja/tembigwái) de Ñande Ramõi, cada um recebeu um canto-reza particular para resguardar aquela camada de tempo-espaço celeste (yvate jỏary) para assim impedir que Ñande Jarý pudesse alcançá-lo.

Até a criação deste tape rendy (caminho-trajeto luminoso) que separou a superfície terrestre do céu, Jorge e Floriza diziam que a terra era uma plataforma plana e contínua ( yvy rupa) sustentada pelos xiru gwasu e seus tekojara, traduzido na expressão de Seu Jorge como os guardiões dos xiru. Os xiru são imanentes a cosmogênese kaiowá, assim como Jasuka. Inclusive, segundo um comentário de Roseli Concianza, tudo que existe no mundo kaiowá seria decorrente do encontro entre a ação do princípio cosmogônico inerente a existência de Jasuká, que esfriou os xiru recém-surgidos: Jasuká heteombo'roy xiru oje'hujeko’aku - "Jasuka foi quem esfriou os primeiros xiru que apareceram, porque eles ainda eram bravos".

A fala da Roseli, nhandesy kaiowá, deixa entrever uma ideia que na cosmologia kaiowá se verifica a inexistência de um estado a priori das coisas no mundo, porque tudo é efeito de coisas que se fazem ou são feitas através de outras e vice-versa, que emergem e são criadas através de diferenças autogenerativas (o’jera) que produzem mais e outras relações. Dona Roseli foi taxativa em um comentário em explicitar que não é possível estabelecer quem surgiu primeiro, Jasuka ou Xiru, mas que foi a partir da conjunção entre eles que as coisas do mundo começaram a acontecer. Ou seja, se é um equívoco generificar Jasuka como feminino e o Xiru como masculino e, por isso, Dona Roseli foi assertiva em estabelecer que não existe subordinação entre eles por um marcador de prestígio fixado no gênero masculino. Por sua vez, se não há uma correspondência direta dos entes primordiais a tipificações de gênero, que tenderiam a definir estes entes apenas como feminino ou masculino, pode-se pensar de forma análoga ao prestígio que homens e mulheres detém como qualidade correspondentes, mas não como idênticas ou englobadas uma pela outra, em uma perspectiva hierárquica.

O que as narrativas indicam são possibilidades de deslocamentos de perspectivas capazes de desestabilizar cristalizações etnológicas que pré-definem posições de uma hierarquia entre homens e mulheres. Assim, como já foi defendido por Rosa (2015), Lea (2015), Seraguza (2013), e por mim mesmo (CARIAGA, 2015), não se trata de transliterar a categoria gênero para o mundo ameríndio, mas as concepções e categorias nativas podem apontar que os problemas engajados nas relações entre e através dos gêneros não são apenas "problemas das mulheres", mas são problemas na produção da vida social "tomando o gênero como metáfora para as oposições convencionalizantes que as pessoas conferem ao mundo, estas estabelecem oposições em seus próprios corpos" (BUCHBINDER; RAPPAPORT apud STRATHERN, 2006: 281). Tal observação pode nos afastar de noções de proeminência do "mundo masculino" diante do "mundo feminino" como se fossem resultantes de um mundo principiado por um ou outro, mas a partir das conjunções e disjunções, como me ensinou Dona Roseli. 
Voltando aos diálogos com Jorge e Floriza, ela fez questão de afirmar que: Nande Jarý não ficou parada, esperando. Ela (Ñande Jarý) foi atrás dele (Ñande Ramoí), mas foi fazendo as coisas dela, procurando ele, ela foi descobrindo mais coisas e aprendendo outras coisas. Segundo a narrativa do casal de xamãs ao perceber o abandono de seu esposo, Nhande Jarý saiu da ogusu (casa comunal kaiowá) em sua procura. Contudo, naquele momento, a superfície terrestre era reduzida e à medida que ela seguiu entoando seus cantos-rezas, o plano terrestre foi se alargando horizontalmente através dos caminhos terrestres (tape poî). Dona Floriza relatava que ao caminhar na procura de seu cônjuge, Ñande Jarý teve que criar coisas para que não passasse fome, pois estava longe de sua casa (ogusu) e de sua roça (kokuê), para que não prejudicasse o bem-estar dos filhos em seu ventre, mas que isso só foi possível com o auxílio de outros tekojara que compadecidos com seu estado cooperaram com ela a ajudando ${ }^{24}$.

Até aqui tenho recorrido as narrativas kaiowá sobre o casal demiúrgico em um esforço de apresentar algumas reflexões a respeito da simetria na produção do prestígio entre homens e mulheres na mitologia e os efeitos na moralidade do coletivo. Como mencionei alhures a condição de senioridade não garante compulsoriamente o prestígio a pessoa idosa, isto requer que ela mobilize outras relações sobre as quais ela atue como uma força de atração capaz de sustentar um grupo. A ação de sustentar um grupo é a tradução que entre os Kaiowá é aplicada aos conceitos que indicam a capacidade de uma pessoa estabilizar algum tipo de coletividade, no âmbito do parentesco kaiowá o tropo mais recorrente é jekoha. O termo exprime a habilidade política do núcleo conjugal de uma família extensa (teýi composto minimamente por três gerações articuladas em torno do ramõi (avô) e jarý (avó), que indicam que este casal (omenda jekoha) reúnem qualidades suficientes para juntar o grupo (CARIAGA, 2019; BENITES, 2009; PEREIRA, 2008; 2004).

Ser ramõi e ser jarý não correspondem apenas e diretamente a idade e a descendência, pois o prestígio associado ao status de ser avô e avó é sim em partes qualificado pelas experiências vividas ao longo da vida, mas se não existirem redes de relações estáveis entre a pessoa sênior e ao menos com duas gerações consanguíneas (filhas/os, netas/os) e afins (genros e noras), o qualificador sobre a idade será desprestigioso: tudjá e wãymi. Na língua guarani ambos termos são adjetivos que se referem a condição de velho ou velha, usados também para classificar objetos, animais, artefatos. Todavia, no que toca ao prestígio da pessoa ou do casal, ser identificado somente como tudjá ou wãymi indica que suas atitudes e condições de vida não correspondem aos ensinamentos deixados por Ñande Rãmoi e Ñande Jarý, pois eles são omenda jekoha ñepyrumbi - casal que é suporte, esteio pilar das nossas origens. Deste modo, a existência das formas de prestígio associadas a homens e mulheres é relativa a própria criação do cosmo e dos seres celestes kaiowá, pois como salientaram as ñandesy, tanto o kuña reko, assim como o kuimba'e são os ensinamentos deixados pela produção de diferenças entre Nande Rãmoi e Ñande Jarý, sobre as quais não interessava às minhas interlocutoras e interlocutores definir um estado prístino destas relações, mas apontar os regimes de criatividade produzidos na trajetória do casal e, consequente, os modos diferenciantes de produção de patamares, espaço, técnicas, práticas e regimes de conhecimentos femininos e masculino.

Tais relações apresentam escalas distintas que podem compor uma teoria etnográfica sobre as relações entre homens e mulheres entre os Kaiowá, que modula a percepção de eixos cosmológicos que inauguram séries que articulam proximidade e distanciamento, nós e outros entre seres, planos e patamares humanos e não humanos. Neste sentido, a vida conjugal de Ñande Ramṍi e Ñande Jarý estabeleceu um importante

\footnotetext{
${ }^{24}$ Conversando com a pesquisadora kaiowá Lucia Pereira, mestranda no PPGAnt/UFGD, sobre o tema que ela se dedica, cuidados e a produção de corpos saudáveis entre as mulheres kaiowá, destacava que existiam tekojara masculinos e femininos, ilustrando com a figura da Kajarý, traduzida pela imagem da "Sereia", personagem ligada a maestria dos seres que vivem nos rios. Em comunicação pessoal, Chamorro disse-me que o uso de jary como sufixo, a vários seres míticos, indica o caráter primordial daquele ser, ele é o dono/mestre e xamã principal da sua espécie. Entre os Kaiowá, segundo Chamorro, os donos/mestres possuem gênero: jarý- feminino e jara - masculino.
} 
campo de relações políticas diferenciantes que emergem quando associamos as questões sobre poder entre as mulheres, assim como o poder das mulheres à noção de poder na ontologia e ação política kaiowá, fazendo uso da categoria gênero como uma constelação de relações para pensarmos algo já sugerido por Strathern (2001: 226): Men and women are sources of metaphors about maleness and femaleness, but in combination as well as separation, and this I take as the most interesting "relationship" between them. ${ }^{25}$

As diferenças aqui não existem para serem consumidas, ao contrário, elas criam e são criadas pela instabilidade que delineia a sociocosmologia kaiowá por formas de ação política que se recusam a explicação de "domínios" masculinos e femininos por uma lógica de propriedade, controle e de subordinação das mulheres ao espaço doméstico/natureza a dimensão pública/social dos homens. No caso kaiowá, kuña reko e kuimbảe reko são atravessados pela existência de campos relacionais onde um está imbricado no outro, onde, ao mesmo tempo em que um termo - kuña/mulher e kuimbaie/homem - pressupõe uma exclusividade da perspectiva de um sobre o outro, também indica que uma perspectiva só existe mediante a existência da outra, como exposto por Strathern (2006: 279) "atributos intrínsecos que pessoas masculinas e femininas estão numa perpétua relação de diferenças". Contudo, volto a insistir que conceitos nativos de trocas entre homens e mulheres kaiowá não se apreendem metonimicamente ao casamento, mas em relações que se transformam em outras relações e composições para além das dinâmicas matrimoniais, podendo ser vistas em outras formas de composição de relações como entre irmãos e irmãs, tias/tios e sobrinhos/sobrinhas, avós e netos que se expressam na produção de grupos para a condução do xamanismo, da produção agrícola, em coletivos de políticas culturais e nas retomadas de seus territórios tradicionais (CARIAGA, 2019; CRESPE, 2015; SERAGUZA, 2013).

As narrativas sobre Ñande Jarý e Ñande Ramõí marcam um tempo mítico onde houve muitas criações originais inerentes ao mundo onde tudo era possível de ser criado, pois era um tempo que tudo era novidade, como disse Dona Floriza. O fim da busca de Nande Jarý por seu esposo é trágico. Desorientada pelas divergências entre os gêmeos que ela carregava no ventre, que mesmo em gestação já se comunicavam com ela, acabou confundindo o caminho e foi em direção a Morada da Onças-Primordiais - Jagwarete'kuê, onde foi devorada pelas Onças-Gente (Jagwaretéava) lideradas pela Avó-Onça - Jagwa Jarý. Com a morte de Ñande Jarý, os irmãos passaram a ser criados como guachos por Jagwa Jary ${ }^{26}$. Conforme expressei no início do texto, a saga dos gêmeos está presente na etnologia guarani desde a obra de Nimuendaju (1987 [1914]).

Existem muitas versões a respeito dos acontecimentos vividos pelos gêmeos desde o assassinato de sua mãe até o momento em que tornaram entes celestes estruturais a cosmologia e moralidade guarani. Não seria prudente se focar numa revisão da bibliografia disponível sobre o conjunto mítico de relações e transformações produzidas pelas diferenças entre Kwarahy (Sol, Irmão mais velho) e Jasy (Lua, Irmão mais novo), pois a intenção não é produzir uma hemeroteca do tema na etnologia guarani, mas contribuir com o adensamento sobre as ontologias políticas no mundo ameríndio a partir das variações que emergem na interlocução com as pessoas que se propõe a narrar tais histórias, na qual a reflexão é sobre o que dito se torna indissociável, desviando de pressupostos que os mitos contém em si uma substância primordial.

\footnotetext{
${ }^{25}$ Tradução minha: Homens e mulheres são fontes de metáforas de masculinidade e feminilidade, mas em combinação, bem como separação, e isso eu considero o "relacionamento" mais interessante entre eles.

${ }^{26}$ Guacho é uma categoria do parentesco kaiowá aplicada aos filhos por adoção. Entretanto, como destaca Pereira (2002) o emprego da palavra guacho demonstra que esta dinâmica entre os Kaiowá é um mecanismo recorrente na ampliação do número de pessoas para a composição de uma parentela para fins de aumento do prestígio de um casal. Entretanto, dependendo da distância consanguínea da criança em relação ao casal adotivo, sua posição será bastante periférica no grupo, desempenhando atividades laborais e de cuidado de outras crianças. Sua posição frágil é expressa até mesmo no vocativo de parentesco, pois, é comum os pais chamarem de cheray'angá - " $a$ sombra do meu filho", contudo, se esta distância for menor, como em casos onde a criança a seja adotada por um tio ou tia materna ou avós, ela será criada como um filho che memby (meu filho/a).
} 
Sob este aspecto, procurei desenvolver na tese estas questões a partir da narrativa de meus interlocutores que vivem na Terra Indígena Panambizinho, em particular com pessoas da família Concianza (CARIAGA, 2019). O conjunto mítico que gravita em torno dos gêmeos é tão extenso que dediquei um capítulo para nossos diálogos sobre o tema dos caminhos, criações e transformações iniciadas na saga dos irmãos. Considerando a extensão da narrativa trago para o artigo uma versão condensada das narrativas focadas após os gêmeos descobrirem que foi Jagwa Jarý que consumiu sua mãe. Kwarahy, como primogênito do casal (rikeý) desde a barriga da mãe já deixava evidente suas diferenças de habilidades e qualidades como irmão maior em relação ao seu irmão menor (tyvyry). Esta condição faz com que seu pai, Ñande Ramõi enviasse a ele as ñembo’e ñepyrumbi ("primeiros cantos-rezas") e o mbaraká que transformaram seu corpo ${ }^{27}$ que o tornou capaz de enxergar a "forma real" dos corpos de seus parentes adotivos, ou seja, como Onças.

Durante uma festa na qual Jagwa Jarý recebeu vários convidados, Kwarahý auxiliado por Jasy, portando seu mbaraká entoando os cantos-reza retirou dos convidados o maior atributo compartilhado por todos, a comunicação e assim tornou-os incapazes de se reconhecerem mutuamente como "humanos-parentes" e estes convidados foram se esparramando (osarambipa) pelas matas e florestas, assumindo formas animais e características morais que produziram perspectivas sobre a diferenciação a respeito da existência de um "nós/humanos" estruturalmente relacionado ao seu par de oposição "outros/animais ${ }^{28}$. Ao fim do banquete Kwarahý tomou para si o fogo culinário das Onças-Primordiais. Tal ação fez com que as onças se tornassem o personagem máximo da alteridade e da predação, da anti-troca na cosmologia kaiowá.

Em síntese, a animalidade dos animais ( $m y m b a)$ para os Kaiowá é marcada por uma condição de ruptura no reconhecimento deles como humanos pela perspectiva kaiowá sobre sua própria humanidade (ore reko). Deste modo, no pensamento mítico o fim do tempo em que a humanidade era a condição compartilhada por todos os entes, com o surgimento dos animais estabeleceu um grande intervalo nas transformações, produzindo distanciamentos entre os seres celestes e os demais que passaram a viver como animais. Este tempo é pensado como a ruptura da condição primordial de existência no Yyy Akandire (Terra Perfeita, onde os seres não morrem) que inaugurou novas concepções de tempo/espaços e regimes de conhecimentos importantes à cosmologia $\mathrm{e}$ moralidade kaiowá: arandu ymaguare - tempo/espaço/modos de conhecer dos antigos, arandu kóanga - tempo/ espaço/modos de conhecer no presente e arandu pyahu - tempo/espaço/modos de conhecer para o futuro.

Estas novas formas de relação com o tempo, o espaço e de modos de ser são também efeitos das transformações derivadas das criações e caminhos que Kwarahý e Jasy iniciaram em consequência da procura da morada celeste de Ñande Ramõi. Para conseguirem alcançar o Kurusu Ambá (patamar celeste mais elevado da cosmografia kaiowá), Kwarahý protagonizou o início de muitas atividades técnicas agrícolas, de caça, regimes de conhecimento e princípios do xamanismo, mas era o tempo todo atrapalhado por seu irmão caçula, que se envolvia com conflitos e problemas com outros tekojara devido sua imaturidade, tendo que o tempo todo ser socorrido, assim como Jasy tentava imitar as criações do seu irmão mais velho, produzindo cópias defeituosas.

\footnotetext{
${ }^{27}$ Segundo meus interlocutores as transformações no corpo de Kwarahý, destacadamente a audição e visão, garantiriam a ele uma amplificação dos poderes recebidos e o tornaram o primeiro hechakáry entre os Kaiowá. Este termo é usado para identificar os xamãs que alcançaram durante a vida o estado de plenitude, maturação de seus corpos (agwyje), que os tornam capazes de transitar e se comunicar com os seres de diferentes planos e patamares do cosmo.

${ }^{28}$ Estas transformações são centrais a formulação sobre os efeitos cosmológicos e sociológicos que as cosmologias ameríndias produzem a partir dos câmbios de perspectivas associados aos pronomes que definem um" nós" e um "eles", como elaborada na síntese etnográfica definida como perspectivismo ameríndio por Viveiros de Castro (1996). Entre os Kaiowá este jogo de perspectivas pode ser compreendido através da bifurcação da própria noção de "nós": existe um nós inclusivo e coletivizador expresso pela palavra ñande que pode associar uma ampla gama de seres ao conjunto "nós" e outro, identificado como ore, que exclui de imediato todos os que não falam língua guarani e se identificam como Guarani, mas pode ser usado de maneira tão restritiva que recusa até mesmo outros Kaiowá de outras parentelas e/ ou território (CARIAGA, 2019).
} 
$\mathrm{O}$ ato mais expressivo de diferenciação e simulacro é quando Kwarahy subindo ao céu tomou a forma do Sol (kwarahy) e assim passou a iluminar o dia e Jasy, na tentativa de imitá-lo tomou um caminho falso deixado pelo seu irmão e passou a viver do outro lado, se tornado Lua, que para iluminar a noite depende do brilho do sol (kwarahy rendy), seu comportamento é visto como inconstante devido a variação de sua forma. Em suma, as diferenças geracionais e o prestígio da senioridade estão intimamente conectados pelos desdobramentos inesgotáveis da oposição mais velho/mais novo canonizados na figura conceitual central ao dualismo em perpétuo desequilíbrio, o que sugiro, no caso dos Kaiowá é acrescentar as relações entre feminino e masculino.

$\mathrm{O}$ que tentei foi inserir nessa lógica da multiplicidade uma outra variante: homem/mulher, pois o fundo das narrativas sobre caminhos, criações e transformações partilham questões da moralidade ameríndia, em ambas as sagas dos personagens, casal primordial e os gêmeos são mediadas pôr aquilo que notou Lévi-Strauss (2006) acerca dos grandes e pequenos intervalos: movimentos que ora tornam as diferenças quase imperceptíveis, mas que também podem produzir uma diferenciação explícita. Essas relações instáveis possibilitam com que possamos pensar a conjunção e a disjunção operem pelos mesmos termos a fim de garantir, o que Lévi-Strauss (idem) estabeleceu como o grande gesto diplomático do mundo ameríndio, a boa distância. Avalio que este pressuposto possa ser transplantado para o campo da filosofia política ameríndia se orientando pelo que foi descrito de maneira notável por Perrone-Moisés (2008: 32) "a filosofia ameríndia postula, assim, que diferenças são imprescindíveis, mas não basta que diferenças existam, é preciso que se relacionem. Mas é preciso também que se mantenham diferentes".

O foco do meu argumento não é secundarizar a narrativa sobre os gêmeos em relação ao casal principal, mas emparelhar as duas sagas para extrair delas eventos, situações que dizem respeito sobre como a existência destes pares: Ñande Ramõí e Ñande Jarý, Kwáry e Jasy podem assegurar reflexões sobre moralidade kaiowá que se sustenta em um gradiente de correlações que asseguram uma boa distância centrada em opor, transpor e justapor os personagens destes pares para extrair daí princípios éticos e morais (SZTUTMAN, 2009; TEIXEIRA-PINTO, 2009). A respeito disso, minha aposta é que para pensar sobre o agência formas de prestígio para pessoa kaiowá é preciso investir na investigação sobre gravita em torno de relações same-sex, cross-sex em composição com dinâmicas same-age, cross age para refletirmos sobre singularidades e reversibilidades nestas comparações (STRATHERN, 2001). Todavia, as diferenças não disruptivas ou consumptivas, o distanciamento não pode ser mínimo e nem podia ser máximo, para isto, os conjuntos míticos sempre produziram séries de relações intermediárias. Esta dinâmica povoa a filosofia do pensamento indígena, indo desde a noção de pessoa, chegando até escalas mais amplas da vida, pois, como refinou Lévi-Strauss (1993: 206) “a América, contudo, a desigualdade se mantém e ganha progressivamente todos os domínios: a cosmologia e a sociologia indígenas lhe devem sua mola mestra”.

\section{Reflexões a se seguir...}

Assim, se tomei como ponto de partida para a elaboração de uma descrição sobre o fazer político entre os Kaiowá, focada nas relações e diferenças constituídas através da expansão e transformação do cosmo e da ação do casal demiúrgico, isto não torna inválido as contribuições que me trouxeram até aqui. O movimento que me trouxe até aqui provêm do efeito de discussões etnográficas sobre a centralidade que as relações geracionais e de gênero tem na ação política kaiowá, não como se fossem uma consequência da vida atual, mas por conectarem modos de relações que aglutinam questões associadas ao prestígio político imanente das narrativas míticas. Nos termos de Perrone-Moisés (2012: 861) trata-se aqui de experimentar a mitologia com lugar de reflexão ameríndia a respeito do que chamamos de política, via de acesso ao que poderíamos nomear — ainda por inspiração lévistraussiana - a armação de uma filosofia política ameríndia. 
Não que os mitos kaiowá sejam a forma irredutível do pensamento ou que existam somente como repositórios da tradição e dos valores tradicionais, mas como indicam Sztutman (2009) e Teixeira-Pinto (2009), o pensamento indígena opera por escalas e alternâncias próprias de formas éticas e morais imanentes aos mitos, isto é, se trata da moralidade em termos e conceitos ameríndios que penso que podem ser transbordando para outras direções, como o fazer político, não se restringindo ao "tempo mítico", porque o mito não está retido em um tempo. Como aponta Sztutman (2009: 312-313) os seus mecanismos de reversibilidade, ainda que relativos, surtem efeito sobre o real, o efeito de reorganização tanto cognitivo, quanto sociopolítico.

Deste modo, a emergência de novas formas de prestígio e de produção de coletivos, não é apenas resultante das consequências históricas do processo de confinamento e da intensificação das relações com os brancos, mas são potentes formas kaiowá de criatividade que conjugam saberes, poderes e tecnologias para produzir formas de ação política que conjugam moralidades do tempo dos antigos (arandu ymagware), com outros modos que emergem diante da experimentação e novidade dos tempos atuais (arandu pyahu). A proposição que trago procura adensar o escopo das teorias kaiowá sobre a filosofia política sem defini-las em termos, mas sim, em dar mais relevo às relações entre partes e, neste caso, apostando na tradução antropológica de sua política em termos etnográficos, não é a procura dos aspectos fundamentais ou das origens da política no mundo kaiowá. A tarefa que cabe a teoria antropológica (e aos antropólog@s) é se corresponsabilizar na tarefa de descrição de modos múltiplos do fazer político, sempre em colaboração e reflexão crítica com seus interlocutores.

\section{Referências}

BARTOLOMÉ, Miguel A. 2009. Parientes de la selva: los guarani mbya de la Argentina. Asunción: CEPAG.

BENITES, Tonico. 2009. A escola na ótica dos Áva-Guarani: impactos e interpretações indígenas. Rio de Janeiro-RJ: Dissertação de mestrado em Antropologia Social, Museu Nacional/Universidade Federal do Rio de Janeiro.

CADOGAN, León. 1959. “Ayvy Rapyta. Textos Míticos de los Mbyá-Guarani del Guairá". USP/FFLCH, Boletim no 227, Antropologia n $n^{\circ}$.

CARIAGA, Diógenes E. 2019. Relações e diferenças: a ação política kaiowá e suas partes. Florianópolis-SC: Tese de doutorado em Antropologia Social, Universidade Federal de Santa Catarina.

. 2015. "Gênero e sexualidades indígenas: alguns aspectos das transformações nas relações a partir dos Kaiowá no Mato Grosso do Sul”. Cadernos de Campo, n. 24: 414-464.

2012. As transformações no modo ser criança entre os Kaiowá de Téýikuê - Caarapó, MS (1950-2010). Dourados-MS: Dissertação de mestrado em História (História Indígena), Universidade Federal da Grande Dourados.

CHAMORRO, Graciela. 2008. Terra madura - Yvy Araguyje. Dourados: Editora UFGD.

. 1995. Kurusu Ñengatu: palabras que la historia no podria olvdidar. Asunción/São Leopoldo: CEPAG/IEPG-COMIM.

CLASTRES, Hélène. 2007. Terra sem mal. Corumbiara: Editora Tapé.

CLASTRES, Pierre. 2004. Arqueologia da violência. Pesquisas de Antropologia Política. São Paulo: Cosac \& Naify. 2003. A sociedade contra o Estado. Pesquisas de Antropologia Política. São Paulo: Cosac \& Naify. 
1990. A fala sagrada. Mitos e cantos sagrados dos índios Guarani. Campinas: Editora Papirus.

CRESPE, Aline C. 2015. Mobilidade e temporalidade kaiowá: do tekoha a reserva, do tekoharã ao tekoha. Dourados-MS: Tese de doutorado em História (História Indígena), Universidade Federal da Grande Dourados.

GIBRAM, Paola; KLEIN, Tatiane. 2020. "Entre tỹhn e mborahei: cantos e movimentos kaingang e kaiowá". Ilha - Revista de Antropologia. No prelo.

JOÃO, Izaque. 2011. Jakaira Reko Nhepyrũ Marangatu Mborahéi. Origens e fundamentos do canto ritual Jerosy Puku entre os Kaiowá de Panambi, Panambizinho e Sucuri'y. Dourados-MS: Dissertação de mestrado em História (História Indígena), Universidade Federal da Grande Dourados.

LADEIRA, Maria I. 2007. Caminhada sobre a luz do luar. Território mbyá à beira do oceano. São Paulo: Editora UNESP.

LEA, Vanessa R. 2015. "Foucault (parcialmente) vindicado no Brasil Central: sexualidade como um fundamento da vida”. Cadernos de Campo, n. 24: 427-440.

LÉVI-STRAUSS, Claude. 2006. A origem dos modos à mesa (Mitológicas v. 3). São Paulo: Cosac \& Naify. 1993. História de Lince. São Paulo: Companhia das Letras.

MELIÀ, Bartomeu. 2016. Mundo guarani. Asunción: Servilibro.

2004. "La novedad guarani (viejas cuestiones y nuevas preguntas). Revisita bibliografica (19872002)”. Revista de Indias, v. LXIV, n. 230: 175-226.

MELIÀ, B.; GRÜNBERG, G.; GRÜNBERG, P. (org.). 2008, 2a ed. Etnografia guarani del Paraguay contemporaneo: los Paĩ-Tavyterã. Asunción: CEPAG.

MELIÀ, B., SAUL, M. V. e MURARO, Valmir (org.). 1987. Guarani - uma bibliografia etnológica. Santo Ângelo: Fundação Missioneira.

MONTARDO, Deise L. 2009. Mbaraka. Música, dança e xamanismo guarani. São Paulo: EDUSP.

NIMUENDAJU, Curt Unkel. 1987 [1914]. As lendas de criação e destruição do mundo como fundamento da religião dos Apapocúva-Guarani. São Paulo: Hucitec.

PEREIRA, Levi M. 2008. "A socialidade na família kaiowá: relações geracionais e gênero no microcosmo da vida social”. Temáticas, ano 16, n. 31/32: 177-203.

.2004. Imagens kaiowá do seu sistema social e seu entorno. São Paulo-SP: Tese de doutorado em Antropologia Social, Universidade de São Paulo.

2002. No mundo dos parentes: a socialização das crianças entre os Kaiowá. In: SILVA, Aracy; NUNES, Ângela e MACEDO, Ana. Crianças indígenas: ensaios antropológicos. São Paulo: Editora Global. p. 168-186.

PERRONE-MOISÉS, Beatriz. 2015. Festa e guerra. São Paulo-SP: Tese de livre-docência em Etnologia Indígena, Universidade de São Paulo.

2011. "Bons chefes, maus chefes e chefões: elementos de filosofia política ameríndia". Revista de Antropologia (USP), v. 54, n. 2: 857-883. 
2008. Abertura. In: CAIXETA DE QUEIROZ, Ruben; NOBRE, Renarde. Lévi-Strauss: leituras brasileiras. Belo Horizonte: Editora UFMG. p. 17-42.

PIMENTEL, Spensy K. 2012. Elementos para uma teoria política Kaiowá e Guarani. São Paulo-SP: Tese de doutorado em Antropologia Social, Universidade de São Paulo.

PIERRI, Daniel C. 2019. O perecivel e o imperecível. Reflexões Guarani-Mbyá sobre a existência. São Paulo: Editora Elefante.

PISSOLATO, Elizabeth. 2007. A duração da pessoa. Mobilidade, parentesco e xamanismo mbyá (guarani). São Paulo: Editora UNESP/ PROEX/NuTI/ISA.

SCHADEN, Egon. 1974 [1954]. Aspectos fundamentais da cultura guarani. São Paulo: EPU/EDUSP.

ROSA, Patrícia C. 2015. "Das misturas de palavras e histórias". Etnografia das micropolíticas de parentesco e os "muitos jeitos de ser Ticuna. Campinas-SP: Tese de doutorado em Antropologia Social, Universidade Estadual de Campinas.

SERAGUZA, Lauriene. 2018. "Mulheres em retomadas: sobre política e relações de gênero entre os Kaiowá no Mato Grosso do Sul”. Tessituras, v. 6, n. 2: 215-228.

.2013. Cosmos, corpos e mulheres kaiowá e guarani. De Aña a Kuña. Dourados-MS: Dissertação de mestrado em Antropologia Sociocultural, Universidade Federal da Grande Dourados.

STRATHERN, Marilyn. 2014. O efeito etnográfico. In: STRATHERN, Marilyn. O efeito etnográfico e outros ensaios. São Paulo: Cosac \& Naify. p. 345-406.

2006. O gênero da dádiva - problemas com as mulheres e problemas com a sociedade na Melanésia. Campinas: Editora Unicamp.

. 2001. Same-sex and cross-sex relations: some internal comparisions. In: GREGOR, Thomas A.; TUZIN, D.(ed.) Gender in Amazonian and Melanesia. An exploration of the comparative method. Berkeley: University of California Press. p. 221-244.

SZTUTMAN, Renato. 2012. O profeta e o principal: a ação política ameríndia e seus personagens. São Paulo: EDUSP.

2009. “Ética e profética nas Mitológicas de Lévi-Strauss”. Horizontes Antropológicos, ano 15, n. 31: 293-319.

TEIXEIRA-PINTO, Márnio. 2009. "Lévi-Strauss, as luzes e os instrumentos das trevas: sobre a moralidade selvagem”. Ilha - Revista de Antropologia, v. 11, n. 2: 193-217.

VIVEIROS DE CASTRO, Eduardo. 1987. Nimuendaju e os Guarani. In: NIMUENDAJU, Curt U. 1987 [1914]. As lendas de criação e de destruição de mundo como fundamento da religião dos Apapocúva-Guarani. São Paulo: HUCITEC/EDUSP. p. xvii-xxx.

Recebido em 27/04/2020

Aceito em 10/05/2020 
